\title{
PROTEÇÃO SOCIAL NA PERIFERIA DO CAPITALISMO considerações sobre o Brasil
}

Marcio Pochmann

\begin{abstract}
Resumo: A diferença entre países do centro do capitalismo e aqueles da periferia, quanto à proteção social, é gritante. Na periferia, houve dificuldade em completar o Estado de Bem-Estar Social, assim como as elites locais barraram os avanços da democracia. Apesar disso, o pequeno aparato social construído a partir da década de 30 passou a ser fortemente questionado desde a crise dos anos 80. Assim, o desafio hoje é vencer a exclusão social, construindo uma democracia social.

Palavras-chave: proteção social; Brasil; Estado.
\end{abstract}

Abstract: The difference between the countries in the center of capitalism and those on its periphery, regarding social protection, is shocking. In the periphery there was difficulty in completing the Social Welfare State, in the same way the local elites blocked the advances of democracy. In spite of this, the small social apparatus constructed since the 1930 's began to be strongly questioned after the 80 's crisis. Thus, the challenge today is to overcome the social exclusion, by building a new social democracy.

Key words: social protection; Brazil; State.

A evolução do capitalismo liberal, no início do século XX, desembocou em dois caminhos distintos: a partir da Revolução Russa, em 1917, ocorreram experiências inéditas de socialismo real, mas, com o passar do tempo, a proposta de ditadura do proletariado foi sendo transformada geralmente na ditadura do partido, e para as demais nações, sem experiências radicais de revolução socialista, predominaram as reformas de caráter socialdemocrata, em que a constituição do chamado Estado de Bem-Estar Social foi a peça fundamental para o estabelecimento da cidadania regulamentada. Apesar da convergência de uma série de reformas socialdemocratas realizadas ao longo do século XX em diversos países, observa-se que a presença plena e mais avançada do Estado de Bem-Estar Social foi uma excepcionalidade das economias que constituem o centro do capitalismo mundial, ou seja, uma minoria de nações e também uma parcela relativamente pequena do conjunto da população mundial. Nas economias capitalistas periféricas, as reformas de caráter socialdemocrata foram de menor expressão, engendrando significativas variações no grau de proteção social.
Foi a partir desse entendimento prévio que este estudo procurou tratar a evolução da proteção social no Brasil. Além desta introdução inicial, apresenta-se, na seqüência, uma breve recuperação das condicionalidades históricas que permitiram o desenvolvimento do Estado de Bem-Estar Social nas economias que constituem o centro do capitalismo mundial. Logo depois, busca-se analisar as condicionalidades históricas do Estado de Bem-Estar Social no Brasil. Dessa forma, espera-se contribuir para um melhor entendimento dos obstáculos e limites da evolução da proteção social num país periférico do sistema capitalista mundial. O texto encerra-se com uma breve conclusão.

\section{PROTEÇÃO SOCIAL NO CENTRO DO CAPITALISMO MUNDIAL}

As economias capitalistas desenvolvidas construíram ao longo do século XX, especialmente a partir do segundo pós-guerra, experiências até então inéditas em termos de avanços na proteção social e trabalhista. Para isso, coube ao Estado um papel singular como participante do 
intenso processo de expansão econômica e do exitoso enfrentamento das iniqüidades geradas no interior das sociedades capitalistas.

As características do Estado intervencionista foram, assim, congruentes com a fase de acumulação de capital marcada pela expansão da concorrência cada vez mais imperfeita (processo de monopolização dos capitais), em que tendeu a diminuir, ainda mais, a capacidade de autoregulação do mercado a partir de suas próprias forças. A politização da vida social, em contrapartida, assumiu papel central na agenda de transformação do capitalismo organizado. ${ }^{1}$

Em seu período de maior glória, quase três décadas sucessivas após o final da Segunda Guerra Mundial (19481973), o chamado Estado de Bem-Estar Social² cumpriu distintas funções estratégicas, todas consagradas ao enfrentamento da pobreza, do desemprego e da desigualdade. Durante esse período, todavia, duas diferenças importantes se fizeram destacar nos propósitos de atuação do Estado de Bem-Estar Social: de um lado, a experiência européia ocidental, que demarcou fortemente seu propósito de atuar ex-post sobre as iniqüidades produzidas pelo desenvolvimento capitalista, por intermédio das políticas de natureza redistributivas (justiça tributária e transferências sociais); e de outro, a experiência norte-americana, que enfatizou bem mais a atuação $e x$-ante sobre as iniqüidades geradas no capitalismo, por meio do sistema educacional e da regulação do patrimônio e do fluxo de renda (imposto de renda negativo). ${ }^{3}$

Por isso, é preciso identificar quais as principais referências estruturantes da constituição e do desenvolvimento do Estado de Bem-Estar Social, com uma espécie de contraponto da experiência de proteção social no Brasil. ${ }^{4}$

\section{Vertentes da Proteção Social}

A emergência do Estado de Bem-Estar Social está fundamentalmente vinculada ao abandono da concepção liberal clássica, originalmente consagrada por Adam Smith, em 1776, no seu livro A riqueza das nações. As críticas ao liberalismo deram vazão ao processo de desmercantilização da sociedade capitalista conduzido por forte pressão social organizada e operada por um novo tipo de Estado.

Em outras palavras, consagrou-se a importante politização das ações de natureza pública executadas pelo Estado, com a finalidade de restringir o papel das forças do livre mercado. Assim, quase um monopólio representado pelo Estado, em maior ou menor grau, foi difundido no centro do capitalismo mundial, com as funções de conceder proteção social a todos cidadãos e garantir a edificação de uma sociedade menos desigual, enfrentando a estratificação imposta pelo mercado.

Para tanto, três foram as principais motivações que iluminaram o Estado de Bem-Estar Social, bem como o seu avanço ao longo do século XX. Primeiro, a motivação de característica pós-liberal - consolidada a partir da Depressão de 1929 -, que permaneceu circunscrita ao ambiente da proteção social e voltada tão somente para os mais fracos, justamente por serem incapazes de viver numa sociedade competitiva. ${ }^{5}$ Segundo, a motivação de natureza mais corporativa, que visou conceder a distinção da proteção social a determinadas categorias ocupacionais consagradas em decorrência de sua importância relativa no interior do mercado de trabalho. Não se trata, todavia, da pressão por uma transformação substancial da sociedade, em busca da eqüidade social, mas da manutenção do status daqueles que em algum momento histórico alcançaram ou continuaram a mantê-lo no interior do mercado de trabalho. ${ }^{6}$

Em outras palavras, a constituição das bases da proteção social dependeu da conformação e da distribuição do poder no interior das sociedades. Nesse caso, em síntese, não houve a constituição de um novo sistema de redistribuição do poder, apesar das garantias de proteção social diferenciadas por segmentos sociais.

Por fim, a motivação de natureza socialdemocrata, que privilegiou a redistribuição da renda gerada por meio da montagem de uma estrutura secundária (fundos públicos), com tributação progressiva sobre os mais ricos e transferências destes fundos públicos para os mais pobres. Não se trata apenas de disponibilizar serviços sociais (educação e saúde) a todos ou mesmo a garantia direta de renda aos pobres, mas de fundamentalmente retirar das forças de mercado a determinação exclusiva da expansão econômica e da gestão sobre a força de trabalho. ${ }^{7}$ A renda primária, embora continuasse a ser repartida de acordo com a posição na ocupação (capitalista, proprietário, banqueiro, trabalhador), acabou por ser alterada substancialmente a partir da instalação de uma estrutura secundária de redistribuição da renda total (efeitos da tributação e transferência de renda via Estado).

Disso tudo surgiram, em menor ou maior dimensão no centro do capitalismo mundial, diversas experiências a respeito de um novo papel do Estado, especialmente constatado pelo comportamento do gasto público complementar à demanda agregada, que até a década de 30 era definida fundamentalmente pelo setor privado. 


\section{Condicionantes Estruturais da Proteção Social}

O desenvolvimento dos regimes de proteção social no centro do capitalismo mundial não indicou uma trajetória simplesmente evolutiva, mas marcada por rupturas, continuidades e transformações históricas. Em todos os casos, pelo menos três condicionantes estruturais se fizeram presentes na fundamentação das estruturas do Estado de Bem-Estar Social ${ }^{8}$ conforme apresentado sinteticamente a seguir.

Lógica Industrial Moderna - O processo de industrialização constitui uma das primeiras condicionalidades estruturais para a emergência do Estado de Bem-Estar Social. Diferentemente dos modos anteriores de produção, a lógica industrial moderna terminou por colocar num mesmo espaço físico uma ampla quantidade de empregados submetida a condições de trabalho e a padrões de vida semelhantes. ${ }^{9}$

Ao mesmo tempo, o emprego assalariado na indústria implicou inseguranças constantes diante do intenso ritmo de produção em grande escala e da introdução de novas tecnologias de gestão mais racional da mão-de-obra, que apontaram para novos tipos de doenças profissionais e invalidez precoce de pessoas idosas, de obsolescência ocupacional para pessoas de baixa escolaridade, de subocupação para crianças e adolescentes, de desemprego de adultos e chefes de família, entre outros. O componente organizativo propiciado pelo enorme contingente de empregados sob o mesmo teto viabilizou o surgimento de um novo tipo de sindicalismo, sobretudo na grande empresa, com preocupações direcionadas à garantia de melhores condições de trabalho e mais alto padrão de vida para todos, diferentemente do antigo sindicalismo de ofício que atuava fundamentalmente para ocupados com maior qualificação. ${ }^{10}$

Na mesma medida, o crescimento da capacidade de produção industrial, com escalas gigantescas e rápidos ganhos de produtividade, passou, por um lado, a oferecer maiores riscos de crises associadas à superprodução e, por outro, a exigir alguma rigidez na contratação de empregados, fornecedores de matérias-primas e de componentes de produção. Em síntese, precisou haver uma hierarquia funcional que definisse desde a progressão hierárquica interna (não se tratava mais de pequenas empresas, em que o dono conhecia todos seus empregados) até a jornada de trabalho organizada para atender à demanda da produção. Havia também o compartilhamento da produtividade, garantindo disciplina e maior intensidade do trabalho.

Assim, a redistribuição de parte dos ganhos de produtividade com empregados ocupados (aumento real de salários e diminuição da jornada de trabalho), com consumidores (redução real dos preços) e com setor público (crescimento da carga tributária) permitiu a convivência menos agressiva no capitalismo desenvolvido, apontando para a consolidação de sociedades menos desiguais, mais homogêneas em direitos e no padrão de consumo. Não se tratava mais do repasse individual dos ganhos de produtividade, mas sim por meio do contrato coletivo de trabalho, da homogeneização dos ganhos entre trabalhadores do chão da fábrica e de ocupações intermediárias de chefia e supervisão.

Democracia de Massa - A partir da lógica industrial orientadora de maiores ganhos de produtividade, houve uma interação significativa de interesses comuns entre a classe operária e a classe média. É nesse parâmetro de ordem mais política que se estabelece um segundo tipo de condicionalidade estrutural que assenta a constituição de regimes políticos da democracia de massa. Com a universalização do voto, superando o estágio da democracia formal, meramente censitária - com votos somente masculinos e apenas para aqueles com posse expressiva de patrimônio e alta renda -, partidos políticos de base operária e de classe média foram organizados, em parte, inclusive, originários da organização de um novo sindicalismo.

Nesse sentido, o avanço da democracia nas economias desenvolvidas possibilitou a chegada da representação operária, inicialmente, no Poder Legislativo e, posteriormente, no Poder Executivo. No Legislativo, partidos de base operária defenderam e aprovaram as primeiras leis sociais e trabalhistas, buscando a generalização para todos ocupados - independentes dos setores econômicos - de conquistas anteriores alcançadas somente por empregados das grandes empresas industriais. Por fim, no Poder Executivo, os partidos de base operária e de classe média - primeiramente com coalizão de partidos e depois com maioria ampla - conseguiram aprovar reformas civilizatórias do capitalismo, como a tributária, a social e a trabalhista. ${ }^{11}$ Pela primeira vez, os ricos passaram a pagar impostos, especialmente com o mecanismo da progressividade sobre a renda e patrimônio, assim como a população pauperizada passou a ser beneficiada tanto pelo acesso aos serviços públicos básicos (educação, saúde, transporte e moradia) como pelos programas de garantia de renda para estudo (bolsa de estudos), aposentadoria (inatividade por 
velhice), situação de invalidez ocupacional (pensão para deficientes físicos e mentais e doenças profissionais) e condição de desemprego (seguro-desemprego). ${ }^{12}$

Em resumo, consolidou-se uma nova estrutura secundária de redistribuição da renda, que veio a se sobrepor à já existente estrutura distributiva primária constituída pela própria dinâmica capitalista (lucros, juros, aluguéis de imóveis, salários e remunerações). Enquanto os ricos passaram a ser tributados consideravelmente (impostos sobre a renda, patrimônio e herança), foi possível formar fundos públicos capazes de financiar a transferência de renda para a população de menor rendimento, permitindo reduzir a pobreza, o desemprego e a desigualdade social no centro do capitalismo mundial. ${ }^{13}$

Sociedade Salarial - Como terceira condicionalidade estrutural na emergência do Estado de Bem-Estar Social, destaca-se a conformação de sociedades salariais nos países centrais, ${ }^{14}$ isto é, sociedades constituídas a partir de mercados de trabalho organizados e assalariados, inclusive com intervenção dos Estados. Nesta organização, havia em torno de 8 a 9 empregos assalariados para cada dez pessoas ocupadas, com estatuto próprio de valores e direitos assegurados previamente tanto pelo contrato coletivo de trabalho, definido por negociação direta entre sindicato e empresários, como por direitos estabelecidos por legislação. A partir disso, normas de consumo e pa-

GRÁFICO 1

Participação das Transferências Sociais no Total da Renda das Famílias França - 1920-2000

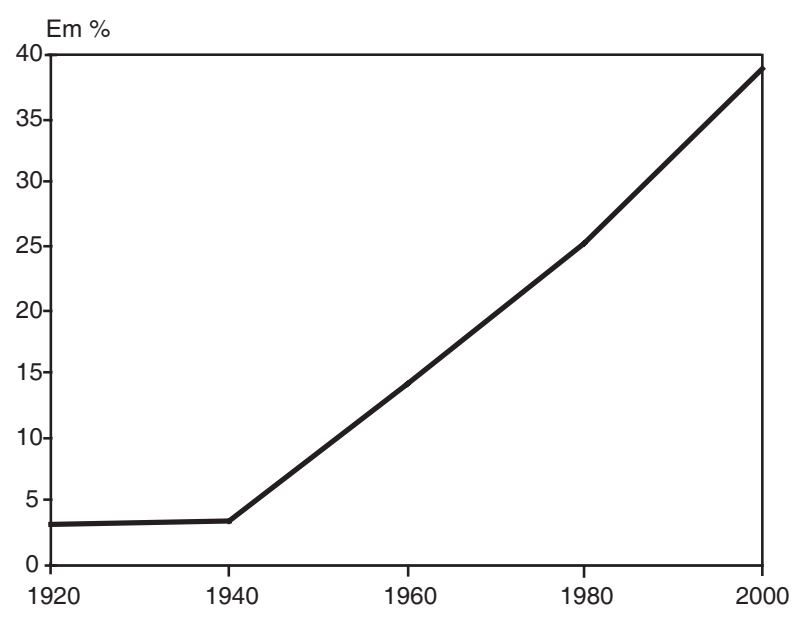

Fonte: Conseil de L'emploi, des Revenus et de la Cohésion Sociale - Cerc. drão de vida superior foram atingidos por distintos segmentos da população trabalhadora, favorecendo uma importante aproximação entre classe média e operária. ${ }^{15}$

Em síntese, a presença de medidas de natureza trabalhista e social protetoras e de bem-estar foi fundamental para atingir maior homogeneidade social no centro do capitalismo mundial. ${ }^{16}$ Em outras palavras, o pleno emprego transformou-se no principal fundamento do processo de estruturação do mercado de trabalho organizado a partir do assalariamento, bem como possibilitou o acesso a um padrão relativamente homogêneo de bemestar, a partir das altas taxas de crescimento econômico entre o final da II Guerra Mundial e o fim da Guerra do Vietnã.

Crise nas Condicionalidades Estruturais - Após quase três décadas de sucesso, o Estado de Bem-Estar Social passou a enfrentar limites consideráveis e obstáculos crescentes à sua continuidade no centro do capitalismo mundial. Diante de um novo ambiente econômico marcado pela profunda desregulação da concorrência intercapitalista e por modificações importantes na base tecnológica, em meio ao predomínio das altas finanças, o Estado de BemEstar Social passou a ser questionado a partir da crise do final dos anos 70 .

De um lado, o baixo crescimento econômico veio a obstaculizar a continuidade do pleno emprego, assim como

\section{GRÁFICO 2}

Taxas de Pobreza ${ }^{1}$ Antes e Depois de Políticas Sociais Países Selecionados - Década de 90

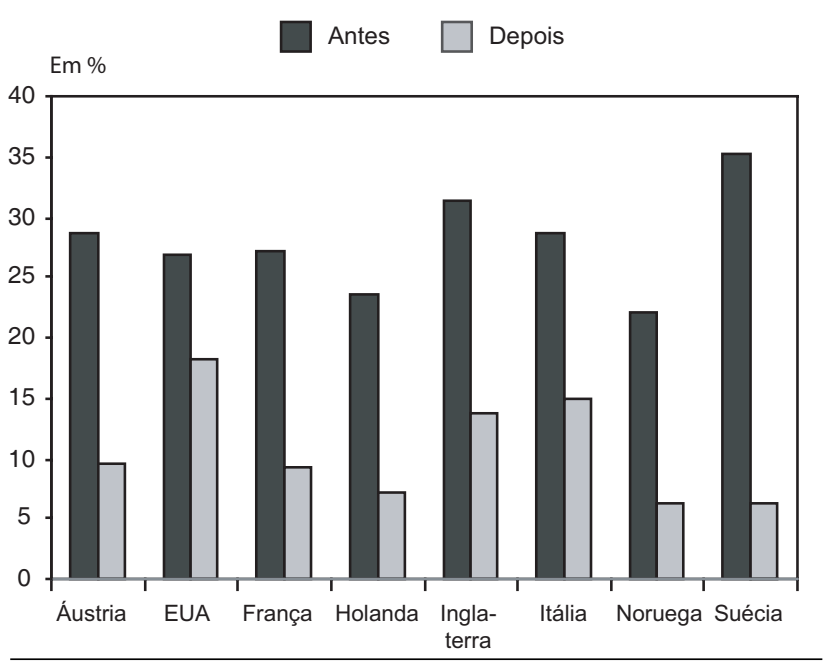

Fonte: Gordon; Townsend (2002).

(1) Definida em até $50 \%$ da renda média. 
as transformações no padrão produtivo inocularam novas formas de trabalho, muitas à margem das contratações coletivas ou legislações existentes. A perda relativa de importância do emprego industrial, envolvida numa outra lógica de produção em redes mundiais, fragilizou compromissos sociais entre empregados e patrões, comprometendo as bases da sociedade salarial e esvaziando o conteúdo dos regimes democráticos.

Ademais, o ambiente de flexibilização dos mercados de trabalho voltou a favorecer a maior desigualdade de renda, surgida de uma nova condição de pobreza e do desemprego, negando a integração social e a homogeneidade no padrão de consumo constituídos a partir do fim da II Guerra Mundial. Não é coincidência que as várias reformas realizadas pelas forças das políticas, a partir do ideário neoliberal, procuraram desviar o papel do Estado de Bem-Estar Social.

Apesar de tudo isso, o Estado de Bem-Estar Social permanece ainda atributo inequívoco da proteção social e trabalhista das classes subalternas no capitalismo avançado. ${ }^{17}$ De todo o modo, a presença do Estado de BemEstar Social nas economias desenvolvidas tem sido fator importante de enfrentamento da pobreza, do desemprego e da desigualdade de renda. Ao final do século XX, o centro do capitalismo mundial acumularia cerca de $1 / 4$ do total de sua população convivendo com renda abaixo da linha de pobreza, caso não houvesse a ação direta e a proteção social que torna residual a pauperização: algo em torno de 1 a cada 10 habitantes.

\section{PROTEÇÃO SOCIAL: A EXPERIÊNCIA BRASILEIRA}

As nações que conformam a periferia do capitalismo mundial não registram os avanços na proteção social e trabalhista observada nos poucos países desenvolvidos durante o século XX, nem mesmo quando foram capazes de apresentar taxas elevadas de expansão de suas atividades econômicas. Esta é precisamente a experiência do Brasil que, por quase cinco décadas no século passado, foi um dos países que mais rápido conseguiram expandir sua economia no mundo, sem obter, todavia, resultados consideráveis no âmbito social.

Para países como o Brasil, que não pertence ao centro do capitalismo mundial, a análise a respeito da proteção social requer considerar inicialmente a condição de pertencimento à periferia econômica, prisioneira do subdesenvolvimento. Mesmo tendo avançado consideravel- mente no processo de industrialização durante o século XX, por exemplo, o Brasil não foi capaz de abandonar as principais características do subdesenvolvimento, tais como a disparidade na produtividade setorial e regional e a permanência de grande parte da população prisioneira de condições precárias de vida e trabalho. ${ }^{18}$

Quando predominaram atividades econômicas primário-exportadoras, durante os primeiros quatro séculos de sua existência (XVI a XIX), o exercício do trabalho esteve submetido à intensa desvalorização, identificada pela imposição do trabalho forçoso e do genocídio indígena, pela escravidão e barbárie de negros e ainda pelo sistema de colonato depreciativo a europeus e asiáticos migrantes. Nessa fase do país, a questão social não apareceu concretamente como um problema à nação, quando muito, como um caso de polícia às elites, a ser enfrentado pela repressão e autoritarismo das forças públicas e privadas.

Por incrível que possa parecer, nota-se, historicamente no Brasil, que diante de um considerável acontecimento - geralmente de natureza externa ao país - surgem algumas poucas brechas para expansão tanto das atividades econômicas como de medidas de proteção social. Verifica-se, inicialmente, como a grande depressão econômica do último terço do século XIX (1870-1890), no capitalismo central, terminou por oferecer oportunidades históricas que produziram algumas brechas a serem aproveitadas pelas economias periféricas.

Justamente durante esse acontecimento de maior importância no capitalismo central é que o Brasil terminou aproveitando uma oportunidade singular para formar as principais bases fundantes do sistema de proteção social. Conforme destacado anteriormente, a difusão do trabalho assalariado e do regime democrático constitui parte fundante dos sistemas de proteção social nas economias centrais, mas que no Brasil foi efetivamente introduzida somente a partir da abolição da escravatura (1888) e da implantação do regime político republicano (1889).

Não se deve esquecer, todavia, que o Brasil foi o último país a abolir o trabalho escravo, impondo uma transição extremamente conservadora para o assalariamento, através da imigração de mão-de-obra européia e asiática, deixando a população negra excluída da possibilidade de imediata integração pelo emprego salarial. Da mesma forma, a implantação do regime republicano não foi nenhum caso esplêndido de participação popular e avanço seguido de maior democratização política do país. 
Tudo isso não nega, contudo, a coincidência com o ciclo de forte expansão nas atividades produtivas, ocorrido no país, sobretudo, com a emergência da economia cafeeira no Sudeste e, por conseqüência, uma nova reinserção econômica nos fluxos do comércio mundial de produtos primários. Isso fica claro já nas duas primeiras décadas do século XX (1900-1920), quando o ritmo de expansão da economia brasileira foi $8 \%$ superior ao da economia norte-americana. Também se comparada à performance brasileira em relação a outros países, nota-se uma melhora considerável, coincidentemente, após a abolição da escravatura e a adoção do regime político republicano.

Observa-se que no período 1870-1890, a evolução do Produto Interno Bruto - PIB brasileiro foi inferior em $70,6 \%$ ao da Argentina, em 36,7\% ao do Uruguai e em $32,6 \%$ ao do México. No período 1900-1920, o ritmo de expansão do PIB brasileiro, embora ainda inferior em $30,3 \%$ ao da Argentina, terminou sendo superior em 20,2\% ao do Uruguai e em 109,7\% ao do México.

Uma outra brecha histórica criada para as economias periféricas ocorreu, mais precisamente, a partir da depressão econômica de 1929, que proporcionou ao Brasil uma nova fase de avanço nas atividades produtivas e no desenvolvimento de um sistema de proteção social. Isso porque a crise no centro do capitalismo mundial, durante a década de 30, abriu um vácuo no antigo modelo econômico agrário-exportador brasileiro, passível de ser ocupado naquela oportunidade tanto por um período de estagnação nas atividades econômicas existentes na época como por uma fase de crescimento em uma outra estrutura produtiva.

Diversos países pertencentes à periferia do capitalismo mundial permaneceram prisioneiros da estagnação produtiva por mais de duas décadas após a depressão de 1929. Quando comparados os níveis de produção de 1950 com os de 1930, nota-se, por exemplo, que países como Índia $(-8,9 \%)$, Indonésia $(-5,2 \%)$, Romênia $(-3,0 \%)$ e Espanha $(-0,1 \%)$ registraram desempenho negativo, em termos de crescimento econômico, enquanto outras nações apresentaram variações médias anuais próximas de zero, como Hungria $(0,2 \%)$, Grécia $(0,5 \%)$, Coréia do Sul $(0,7 \%)$, Iugoslávia $(0,8 \%)$, Honduras $(1,1 \%)$ e Uruguai $(1,6 \%)$.

Para uma crise que veio de fora, o Brasil reagiu muito bem a partir de uma mudança na correlação de forças sociais internas favoráveis à consagração de um novo modelo econômico, capaz de superar a antiga condição de economia agrário-exportadora. Isso não significou uma mera subordinação a reflexos externos, mas sim fruto do estabelecimento de uma nova articulação de classes sociais, responsável pela expansão urbana e industrial nacional que superasse o predomínio das classes proprietárias rurais.

Entre 1930 e 1980, a produção nacional foi multiplicada por 18,2 vezes $(6,0 \%$ ao ano $),{ }^{19}$ o que permitiu constituir uma das mais importantes possibilidades para a consagração de uma nova estrutura produtiva nacional (de base industrial), necessária à conformação do sistema de proteção social no Brasil. Tudo isso, todavia, não se mostrou suficiente para que o país chegasse a apresentar níveis de pobreza, de homogeneização do mercado de trabalho e de desigualdade social comparáveis a países com desempenho econômico similar.

Como se poderá verificar logo a seguir, o país não conseguiu combinar o crescimento econômico com a construção de uma sociedade justa, democrática e socialmente menos desigual. Isso ainda terminou sendo muito mais agravado pelo ingresso da economia brasileira numa fase de estagnação das atividades produtivas a partir de 1981 . Sabe-se que a crise econômica internacional, acompanhada por uma série de ajustes promovidos nos países que compõem o centro do capitalismo, a partir da década de 70, impôs uma nova realidade aos países periféricos.

Novamente uma crise que veio de fora gerou um novo vácuo político interno, que terminou sendo preenchido, lamentavelmente, por uma fase de estagnação produtiva e não pelo crescimento econômico no Brasil, conforme ocorrido nas experiências anteriores.

O mesmo não aconteceu, contudo, com outros países periféricos, que demonstraram capacidade suficiente para ingressar numa nova onda de crescimento econômico. Podem ser destacadas, por exemplo, as economias que registraram rápido crescimento médio anual do produto interno bruto entre 1980 e 2001: Botswana (7,5\%), China (7,3\%), Coréia do Sul (7,3\%), Cingapura (7,0\%), Tailândia (5,9\%), Índia $(5,6 \%)$, Irlanda $(5,5 \%)$, Paquistão $(5,1 \%)$, Uganda $(4,9 \%)$, Indonésia $(4,5 \%)$, Chile $(4,4 \%)$, entre outros.

No Brasil, assistiu-se à constituição de uma nova articulação de classe social responsável tanto pela secundarização do setor produtivo industrial como pelo avanço das classes proprietárias de ativos financeiros. Em função disso, o projeto de desenvolvimento nacional deu lugar gradualmente a um ciclo crescente de financeirização da riqueza, cujo principal sustentáculo de seu financiamento e legitimação política encontra-se no Estado.

O desenvolvimento das atividades produtivas foi obstaculizado, enquanto o sistema de proteção social tem 
sido recorrentemente mitigado pelo contingenciamento de recursos públicos para a esfera financeira e pela desestruturação do antigo papel do Estado. Não tem sido por outro motivo que o país passou a acumular maiores indicadores de exclusão social, a partir do alto desemprego somado à antiga pobreza e desigualdade social.

Sem saídas, o ciclo de financeirização da riqueza depende da lógica de contínua transferência da renda gerada pelo setor produtivo, especialmente da renda do trabalho, bem como da compressão do gasto social. Durante a década de 90 , o rendimento do trabalho perdeu 9 pontos percentuais de sua participação relativa no total da renda nacional, enquanto simultaneamente a carga tributária bruta foi elevada em 10 pontos percentuais.

Esse acréscimo na participação do Estado, no total do excedente econômico, resultou fundamentalmente no esvaziamento da renda das classes trabalhadoras e terminou não sendo alocado adicionalmente no gasto social, mas sim no atendimento dos serviços do endividamento público. Em 2003, por exemplo, quase $10 \%$ do Produto Interno Bruto foi transferido como pagamento de juros ao mercado financeiro, atualmente dominado por apenas cerca de 15 mil famílias.

Nesses termos, um sistema amplo e adequado de proteção social não parece ter viabilidade possível no Brasil. O conhecimento sobre a manifestação atual e a origem da proteção social na periferia do capitalismo pode contribuir para verificar o quanto o Brasil ainda precisa avançar na construção do seu Estado de Bem-Estar Social.

\section{Constrangimentos no Brasil}

Quando são tomados por referência os três indutores principais (lógica industrial, acesso à democracia de massa e conformação da sociedade salarial) que demarcam, no centro do capitalismo mundial, a origem e o desenvolvimento do Estado de Bem-Estar Social, chega-se a um melhor entendimento acerca da evolução da proteção social no Brasil. Sabe-se que a condição de economia periférica implica distinção temporal e qualitativa significativa na constituição da base material referente ao processo de acumulação de capital e de articulação das forças sociais.

Ademais, o acesso à base material necessária à constituição da estrutura industrial não se deu livremente no mercado internacional, mas sim dependente fundamentalmente das brechas históricas abertas a poucas nações. Conforme tratado anteriormente, o Brasil foi ágil em aproveitar algumas delas, especialmente durante as depressões econômicas de 1870 e de 1929, mas, lamentavelmente, desde a crise econômica internacional na década de $70,{ }^{20}$ o país tem recorrentemente descartado as poucas e singulares brechas abertas às economias periféricas.

Como se sabe, o modo de proteção social no Brasil ganhou expressão fundamentalmente a partir da Revolução de 30. Embora não tenha significado de fato uma revolução burguesa no sentido clássico, conforme observado no centro do capitalismo mundial, a Revolução de 30 se mostrou capaz de alterar o jogo político interno que até então prevalecia - por mais de quatro séculos - dependente significativamente das classes proprietárias rurais. ${ }^{21}$

Nesse sentido, a ascensão da burguesia industrial e a emergência das classes trabalhadoras urbanas constituíram novos atores responsáveis crescentemente pelo aparecimento de uma agenda política direcionada à regulação das livres forças do mercado. Em particular, a Consolidação das Leis do Trabalho - que foi fruto de certa coalizão política da burguesia industrial com as classes operária e média -, terminou comportando-se como um entrave diferenciado à hegemonia das classes proprietárias rurais, que não representavam mais do que três mil famílias responsáveis pelo aprisionamento da política macroeconômica favorável ao modelo primário-exportador (taxa de câmbio, impostos e subsídios favoráveis à economia cafeeira).

É importante lembrar que a antiga e primária base industrial - originária em simultâneo com o êxito da economia cafeeira - encontrava-se prisioneira de um modelo de gestão do trabalho completamente ultrapassado (ausência de regulação pública sobre o trabalho e a concorrência intercapitalista). Por isso, destaca-se o papel da regulação pública do trabalho naquela oportunidade no Brasil, porque ela foi sendo consolidada justamente quando a atividade industrial nacional ganhava espaço, deixando no segundo plano as atividades do meio rural.

Até a década de 30, por exemplo, o empregador industrial absorvia praticamente a totalidade do custo de reprodução do seu trabalhador no preço final do produto ou serviço comercializado. Como uma espécie de herança do período escravista, o empregado industrial tinha praticamente a totalidade do seu custo de reprodução internalizado na estrutura da produção, significando, na maior parte das vezes, a responsabilidade da empresa pela constituição e manutenção, além do salário, das chamadas vilas operárias (moradia, educação, saúde, previdência e assistência, entre outros custos). 
A partir da Revolução de 30, quando se estabeleceu o projeto de industrialização, que já era tardio em comparação com as fases de industrialização originária ocorridas no centro do capitalismo mundial, grande parte do custo de reprodução da força de trabalho foi externalizado da estrutura interna de produção da empresa. Em outras palavras, além de cobrir alimentação e vestuário, o salário recebido mensalmente pelo empregado urbano teve que cobrir também despesas com moradia, previdência e assistência, educação, saúde, entre outros.

Nesse sentido, ganharam importância a definição do salário mínimo (criado em 1940) e a estrutura de tributação elaborada com vistas ao financiamento, pelo Estado, das políticas públicas de educação, saúde, previdência e assistência. Todavia, essa nova possível articulação de parte das forças sociais não logrou constituir um amplo sistema de proteção social associado ao avanço da base urbano-industrial. Na realidade, foi estabelecido um sistema de proteção social de natureza meritocrática e particularista, ${ }^{22}$ voltado tão somente aos trabalhadores assalariados com carteira assinada. Como a maior parte das classes trabalhadoras encontrava-se no campo, apenas os empregados urbanos foram beneficiados pelo salá- rio mínimo, assim como por toda a legislação social e trabalhista (Consolidação das Leis do Trabalho).

Ao mesmo tempo, a estrutura tributária implementada naquele momento demonstrou ser regressiva, dependendo de impostos e contribuições sobre o custo do trabalho. Assim, parte importante do sistema de proteção social foi financiada por base contributiva, por tributos indiretos e subvenções fiscais, que, na maior parte das vezes, é regressiva, pois onera justamente a renda dos pobres.

Parte importante dos gastos sociais passou a estar atrelada ao comportamento dos salários e da folha de pagamento (fpag.) formal das empresas, como nos casos da educação pública, que depende do salário-educação (2,5\% da fpag.), da qualificação profissional (1,6\% da fpag.), do entretenimento ( $1,5 \%$ da fpag.), da invalidez por acidente de trabalho (2,0\% da fpag.), da previdência e assistência social (20,0\% da fpag. e até $11,5 \%$ do salário) e da proteção ao desemprego ( $8 \%$ da fpag.). Na totalidade, o financiamento geral da proteção social representou em torno de $1 / 3$ do custo total do empregado urbano, o que tornou o acesso ao contrato formal de trabalho mais difícil e um problema para o acesso e difusão de uma cidadania de natureza regulada. ${ }^{23}$

GRÁFICO 3

Evolução do Índice do Poder de Compra Referente ao Benefício da Previdência e Assistência Social, do Percentual de Aposentados e Pensionistas no Total da PEA e da Participação da Receita Previdenciária no PIB

Brasil - 1940-1990

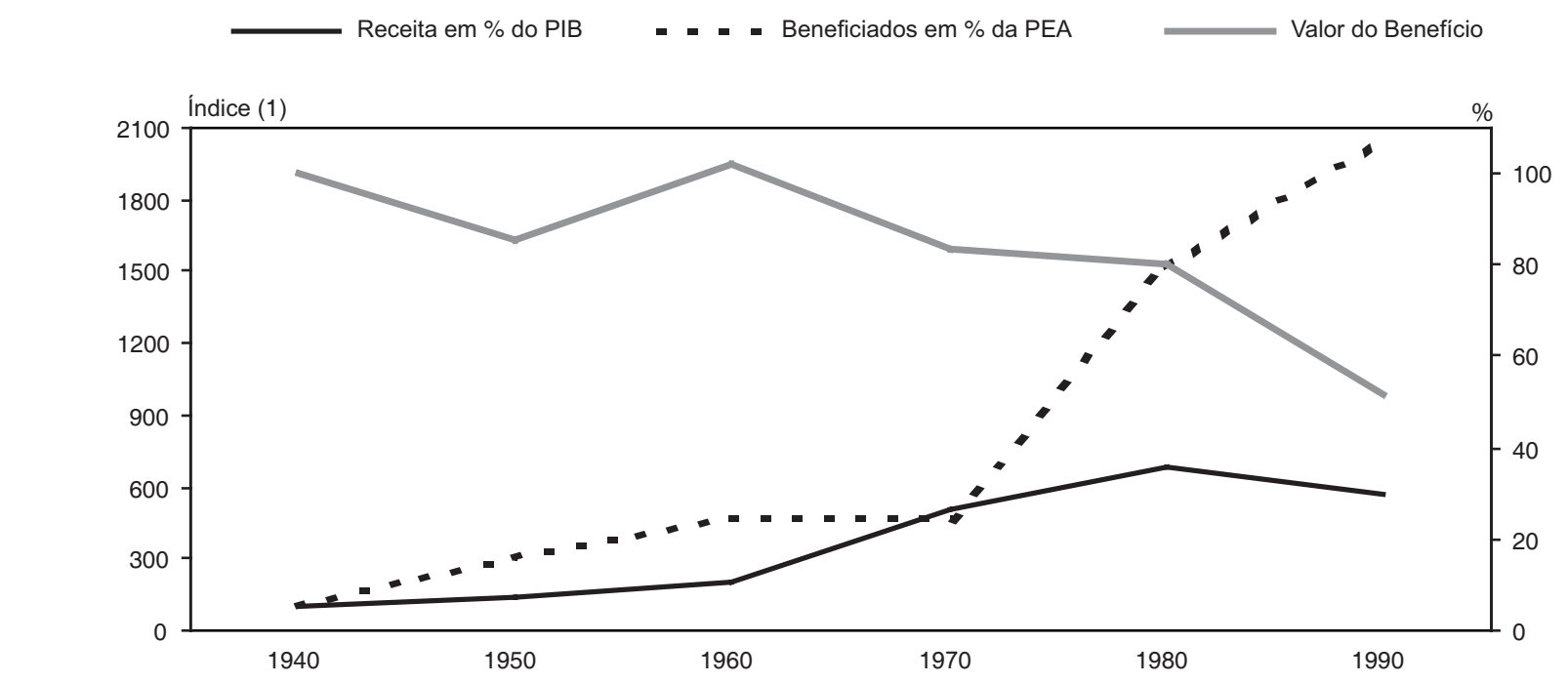

Fonte: Pochmann (1995).

(1) Base: $1940=100$. 
Por outro lado, dada a composição do financiamento do gasto social dependente de subvenções e de receitas contributivas, indelevelmente associadas ao emprego assalariado formal, observou-se que a ampliação da cobertura de beneficiados pelo sistema de proteção social implicou, muitas vezes, queda no valor real do benefício, precarização do serviço ofertado pelo setor público e fragmentação da assistência em bases filantrópicas. ${ }^{24}$

Dessa forma, as restrições no financiamento das políticas de proteção social e a natureza regulada de acesso aos benefícios - vinculada ao emprego assalariado formal -, impediram que a incorporação de novos segmentos populacionais viesse acompanhada da melhora dos serviços ofertados e do valor real pago como benefício social. A perspectiva de universalidade da proteção social terminou sendo postergada, indicando que a incorporação de novos beneficiados (geralmente mais pobres) representasse, em alguns casos, o abandono voluntário de segmentos mais ricos da educação e saúde públicos.

Assim, e isso é muito importante, a classe média não apenas terminou por abandonar a educação fundamental e a saúde pública, para buscar nas ofertas privadas de proteção social, como também deixou de ser parceira na defesa da universalização do sistema de proteção social. Da mesma forma, o corporativismo de certas categorias profissionais mais elitizadas, a meritocracia da escolaridade mais elevada numa sociedade de analfabetos e o particularismo de segmentos ocupacionais de mais alto rendimento contaminaram as possibilidades de maior articulação de interesses e ação política entre classes operária e média no Brasil.

Nesse sentido, também podem ser identificados vários sinais de proximidade das políticas sociais a uma maior privatização do Estado. Seja de parte dos fundos públicos, seja pela gestão terceirizada das atividades de fornecimento de bens e serviços públicos, o setor privado terminou sendo um dos grandes beneficiados pela natureza mais mercantilizada de funcionamento do Estado no Brasil. ${ }^{25}$

Também é necessário frisar como o comportamento real dos salários, especialmente do salário mínimo, foi determinante para o acesso ou não à sociedade de consumo de massa no Brasil. Sem que o poder aquisitivo do salário mínimo acompanhasse a inflação, bem como os ganhos de produtividade, tornou-se difícil a criação de uma sociedade de consumo de massa no país, mesmo para trabalhadores com contrato formal e atendidos pelo sistema de proteção social.

\section{GRÁFICO 4}

Evolução do Poder de Compra do Salário Mínimo Brasil e França - 1950-1990

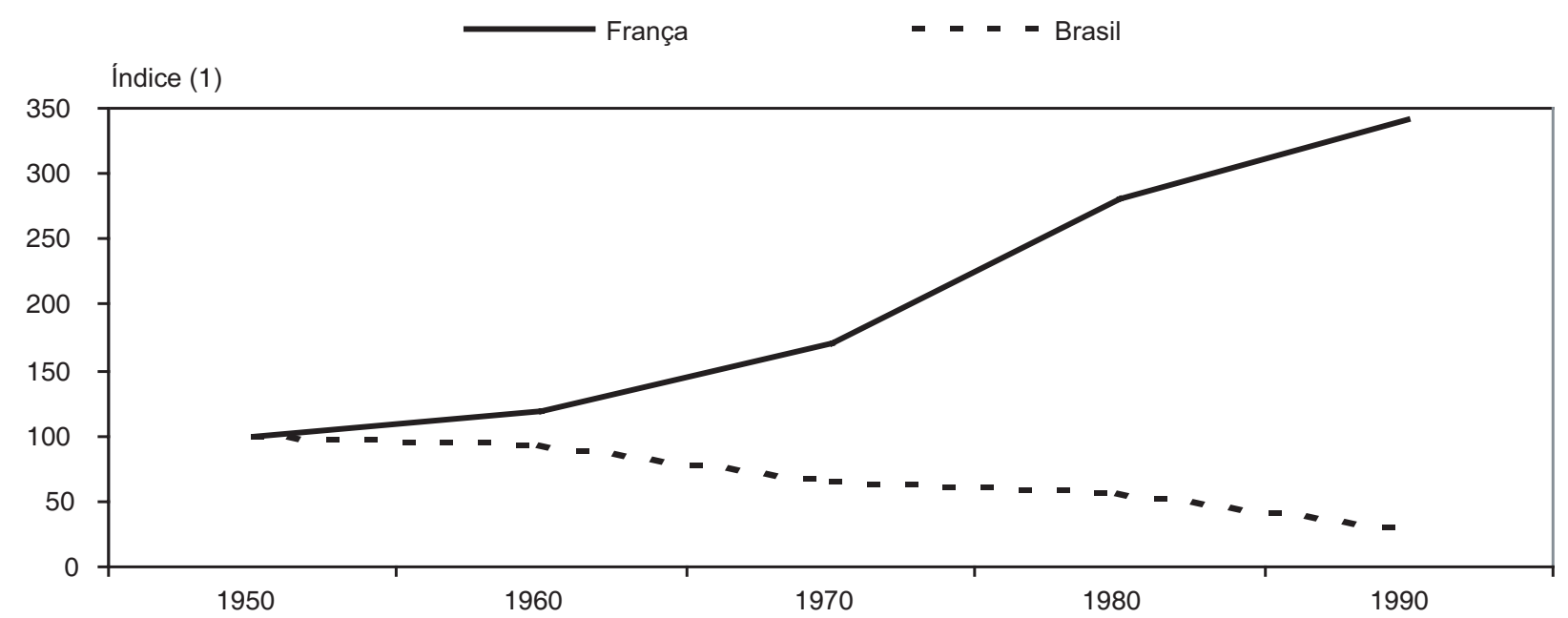


O prolongamento do processo de desvalorização do salário mínimo iniciado pelo regime militar, em 1964, também contribuiu para desfazer a possibilidade de alianças políticas estratégicas entre trabalhadores sindicalizados e organizados nas grandes empresas e o conjunto de trabalhadores de salário de base. Nesse sentido, com a evolução do piso salarial bem acima do valor do salário mínimo para trabalhadores sindicalizados nas grandes empresas, houve o abandono da luta pela elevação do valor real do mínimo nacional, enquanto a maior parte dos ocupados de remuneração de base, sem organização e sindicatos combativos para defender o valor do mínimo nacional, aceitou ampliar a jornada de trabalho (horas extras em excesso) e adiantar a colocação da mulher e de filhos em idade precoce no mercado de trabalho como forma de compensar a queda no rendimento familiar desde a década de 60.

Em certa medida, os sindicatos de trabalhadores, enquanto representantes dos empregados formais, terminaram permanecendo prisioneiros dos interesses de parcelas específicas das classes operária e média. Mesmo assim, a articulação com instituições políticas, mais especificamente com o Partido Trabalhista Brasileiro - PTB, já que os partidos de esquerda estiveram quase sempre na ilegalidade, possibilitou a ampliação lenta e gradual da proteção social para outras parcelas da população trabalhadora, por intermédio de legislação social e trabalhista apropriada, especialmente entre 1946 e 1964.

Apesar disso, por exemplo, em 1923, foi aprovada uma legislação que inaugurou a primeira experiência brasileira de previdência social (caixa de aposentadoria dos ferroviários), que foi modificada posteriormente por lei para as principais categorias profissionais urbanas (institutos de aposentadorias e pensão) a partir dos anos 30. Somente na década de 60 foi constituído, por intermédio de legislação, o fundo próprio de assistência médica e de assistência e aposentadoria para trabalhadores rurais (Funrural), imediatamente à unificação dos fundos de aposentadoria e pensão para empregados urbanos (Instituto Nacional de Previdência Social).

Desde o final da década de 70, o fortalecimento do chamado novo sindicalismo no Brasil permitiu a retomada não apenas da redemocratização nacional, mas também da defesa de uma agenda mais ampla, vinculada aos interesses do conjunto dos trabalhadores rurais e urbanos. Todavia, sem o instrumento do contrato coletivo de trabalho, mesmo após o fim do regime militar (1964-1984), os sindicatos continuaram a depender ainda da legislação para avan- çar a proteção social e trabalhista, seja pela atualização do valor real do salário mínimo, seja pela introdução do décimo terceiro salário, do salário-família, entre outras medidas mais recentes (seguro-desemprego, um terço de férias, redução na jornada de trabalho, etc.). O mesmo também pode ser identificado em relação aos interesses patronais que se mostraram em grande parte dependentes da legislação e do poder policial do Estado, como nos casos da repressão à ação sindical operária, da imposição de arrocho salarial (legislação salarial, 1964/94) e da garantia de financiamento de suas entidades de representação de interesses (tributação parafiscal, como sistema "S" e contribuição sindical).

Por meio de lutas sindicais e políticas partidárias foi possível, pela Constituição Federal de 1988, atingir a unificação do sistema de assistência e previdência social para trabalhadores urbanos e rurais. Apesar da importância do parlamento no desenho legal do sistema de proteção social, a experiência de democracia de massa no Brasil é relativamente contida no tempo. Somente a partir de 1930, por exemplo, que o país superou o estágio da democracia censitária, quando menos de um décimo do total da população votava.

Com o voto universal para a população adulta e escolarizada, o regime democrático ganhou importância inequívoca na constituição do sistema de proteção social. Talvez por isso, toda vez que o movimento popular parecia ganhar força (e maioria no Legislativo ou no Executivo), o autoritarismo foi utilizado por interesses econômicos e políticos contrários a isso, a fim de bloquear as brechas de avanços sociais possíveis, como durante o Estado Novo (1937-1945), no conservadorismo extremo do presidente Dutra (tornou ilegais os partidos de esquerda) e ainda no Regime Militar (1964-1984).

Esse bloqueio da democracia de massa no Brasil, justamente nos momentos cruciais de sua história, evitou a realização das chamadas reformas civilizatórias do capitalismo ocorridas nas economias centrais. Em síntese, o país esqueceu-se da reforma agrária que permitisse redistribuir a concentrada propriedade fundiária, da reforma tributária que tornasse progressiva a estrutura dos impostos, chegando a atingir sobretudo os ricos, e a reforma social que fizesse universal o acesso regulado aos direitos sociais e trabalhistas que permaneceram tão somente direcionados aos empregados assalariados formais.

Sem a constituição de uma estrutura secundária de repartição da renda, assistiu-se, no Brasil, a contínua concentração da renda e da propriedade ao longo do tempo. 
Da mesma forma, políticas de transferência de renda aos estratos mais pauperizados da população praticamente deixaram de ser implementadas, o que implicou constante e abundante pressão de mão-de-obra no interior do mercado de trabalho. Nessas condições, não houve possibilidade de a sociedade salarial ser completada, pois o mercado de trabalho funcionou com enorme excedente de mão-de-obra e diversas formas de ocupações não-assalariadas.

Mesmo havendo ampliação considerável do assalariamento no Brasil, que passou de cerca de $1 / 5$ do total dos ocupados, no final da década de 30 , para cerca de $2 / 3$, em 1980, o mercado de trabalho manteve-se extremamente heterogêneo, tanto no que diz respeito ao fato de o emprego assalariado ser composto por trabalho sem contrato formal, como pela diversidade de ocupações não assalariadas e, na maioria, ilegais. ${ }^{26}$

Ao contrário da sociedade salarial constituída nas economias centrais - responsável pela generalização das condições e relações de trabalho assalariadas para praticamente todos os setores de atividades produtivas -, perpetuaram-se no Brasil relações de trabalho não capitalistas. Setores econômicos como agricultura de subsistência e serviços urbanos vinculados ao abastecimento (pequenas mercearias), lojas e oficinas de reparação e de atendimento pessoal e familiar permitiram que uma verdadeira economia de baixos rendimentos contribuísse para a cobertura de parte importante do custo de reprodução da força de trabalho, mesmo nos grandes centros industriais do país. A autoconstrução de moradias, muitas vezes em terrenos ilegais, transformou-se numa das poucas alternativas criadas pela engenhosidade popular para fazer avançar o atendimento de habitações, de água e luz (famosos gatos).

Isso tornou possível tanto a abertura de imensas frentes de ocupações urbanas sem acesso ao sistema de proteção social, como o barateamento do custo de reprodução do trabalhador formal, que recebeu salários reais decrescentes, especialmente a partir do regime militar. Nesse sentido, o novo contexto projetado pela industrialização nacional terminou combinando o moderno com velhas formas não capitalistas de ocupação de mão-deobra.

Tudo ocorreu, é claro, durante o auge do ciclo de industrialização (1930-1980), quando o país experimentou taxas inéditas de expansão da produção. Acontece, todavia, que a partir de 1981 o ciclo econômico foi invertido, com inegáveis conseqüências socioeconômicas para o país. Num quadro de ruptura de vários elos das cadeias industriais, que forçam fundamentalmente a especialização produtiva e a concentração da renda em segmentos de baixo valor agregado e conteúdo tecnológico, a nova lógica de competição industrial contribui para o desmantelamento da desregulação do

GRÁFICO 5

Evolução da Participação do Rendimento do Trabalho da Renda Nacional

Brasil e Estados Unidos - 1959-2000

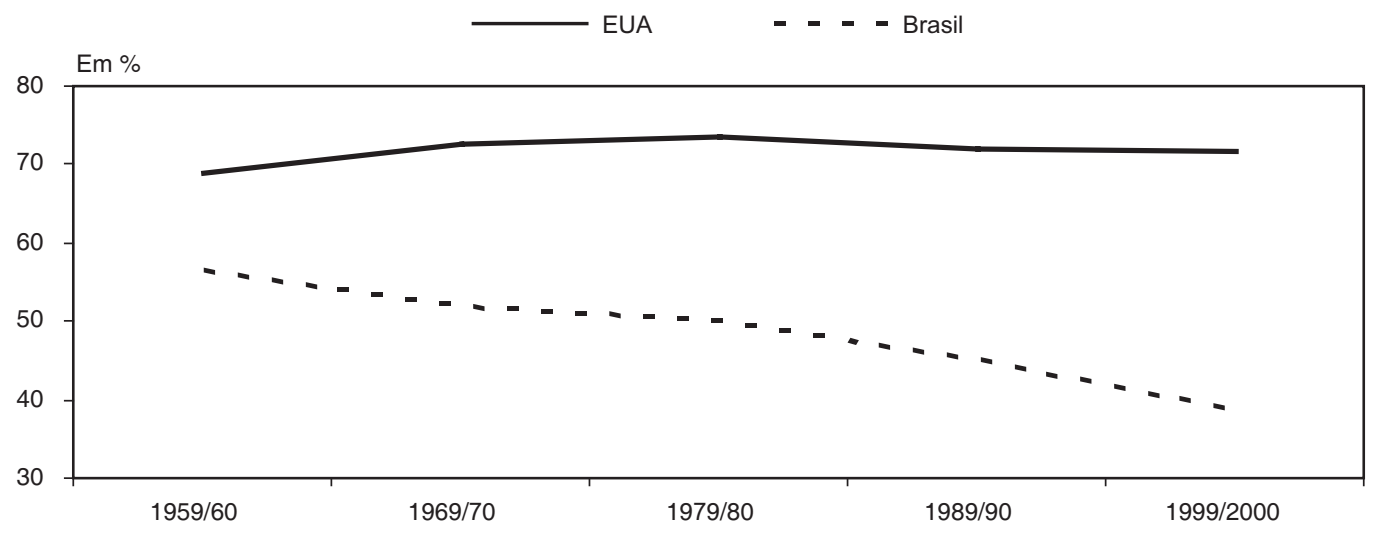

Fonte: Mishel (2003); Pochmann (2001) 
mercado de trabalho. Assim, o desassalariamento passou a ser a norma, com intercruzamento no interior das plantas produtivas de distintos segmentos ocupacionais: trabalho autônomo, trabalho em cooperativas (falsas ou não), programas de estágios, trabalhadores assalariados contratados indiretamente pela terceirização, empregados assalariados diretamente contratados.

Entre 1992 e 2002, por exemplo, observa-se que 2/3 do aumento da ocupação na indústria de transformação no Brasil ocorreu por intermédio do trabalho autônomo. Ao mesmo tempo, nota-se também que, na década de 90 , sete a cada dez ocupações criadas pertenceram a somente quatro famílias ocupacionais: trabalho doméstico, ambulantes, serviços de limpeza e manutenção e segurança. ${ }^{27}$

Enfim, uma profusão ainda maior (heterogênea) de ocupações tem sido consagrada a partir das últimas duas décadas do século XX, implicando geralmente o exercício precário do trabalho, sem regulação pública e distante da organização sindical. Mesmo com a Constituição Federal de 1988, que tinha por perspectiva a consolidação de um sistema de bem-estar social no Brasil, verifica-se na prática que os avanços foram relativamente pequenos.

Sinais de retrocessos no sistema de proteção social no Brasil não são desprezíveis, diante da queda da renda do trabalho, da expansão do desemprego aberto e de ocupações precárias. Em contrapartida, a ampliação do gasto com previdência, assistência social e garantia de renda (previdência aos trabalhadores rurais, Lei Orgânica da Assistência Social e programas de transferência de renda) ajuda a combater a pobreza e a desigualdade social, ainda que sem capacidade de substituir a renda do trabalho.

\section{Desafios da Proteção Social}

Existe um importante contraste dos obstáculos e limites do Estado de Bem-Estar Social no Brasil e no centro do capitalismo mundial. Ainda que possam, em alguma medida, ser comparáveis, nota-se que no Brasil a situação é de outra natureza.

Como o Brasil encontra-se invadindo uma terceira década perdida em termos de crescimento econômico desde 1981, cabe inquestionavelmente definir o imperativo da expansão produtiva a rápidas taxas anuais e sustentadas no tempo como condição necessária para o desenvolvimento social. É claro que está sugerindo-se a expansão da renda como meio para sua melhor redistribuição social.

Isso porque se sabe que o país possui ainda uma importante questão demográfica a superar. Embora esteja passando pela transição demográfica que torna crescentemente maior a população com elevada faixa etária, a expansão anual da População Economicamente Ativa tem sido acima de $3 \%$ como média anual. Dessa forma, o crescimento econômico precisa ser elevado, ao contrário de países de centro do capitalismo mundial que possuem praticamente uma população estagnada ou com baixa variação demográfica.

O Brasil tem espaço para racionalizar e buscar a eficiência do gasto social, embora parcela importante da população não contribua no financiamento social. Observa-se, por exemplo, que apenas uma pessoa a cada três encontra-se protegida pela regulação do mercado de trabalho, enquanto somente uma a cada duas contribui para a previdência e assistência social.

Tudo isso sem comentar o atraso da atuação das políticas sociais que são operadas por um padrão de gestão pública ultrapassado. A fragmentação do gasto social com ações setorializadas implicam somas elevadas somente no custo-meio de operação das políticas públicas, que na maior parte das vezes concentram-se nas medidas de natureza assistencial. Diante da dispersão de objetivos, permanecem elevados o clientelismo e o paternalismo das políticas sociais que terminam por obstruir a perspectiva necessária da emancipação social e econômica da população assistida. Da mesma forma, as iniqüidades não se encontram somente na natureza do gasto social, mas fundamentalmente na forma de arrecadação tributária.

No Brasil persiste a regressividade na estrutura tributária, que termina onerando muito mais os pobres do que os ricos. Assim, não somente o gasto social, mas sobretudo a arrecadação tributária constituem fundamentos potencializadores da desigualdade que já vem originária da distribuição primária da renda.

Por fim, cabe chamar a atenção para o desafio da maior importância da política social no Brasil, que é o de realmente democratizar a democracia representativa. Sem experiência democrática consolidada ao longo do tempo, o país tem concentrado não somente a renda, mas fundamentalmente o poder. É difícil negar que o processo de exclusão social no Brasil não esteja ligado umbilicalmente com a concentração de poder. Nesses termos, a pobreza no país é de natureza política, que faz do pobre alvo de mera assistência, quando muito.

Sem retomar o rumo político perdido desde a década de 80 - ao colocar para um conjunto mínimo de famílias ricas o aprisionamento da política macroeconômica de sustentação do ciclo de financeirização da riqueza no Brasil -, as ações sociais podem, cada vez mais, garantir uma 
maior funcionalidade com a manutenção da pobreza e exclusão social. Assim, democratizar a democracia e avançar no modelo econômico que garanta expansão produtiva constituem bases necessárias para o sistema de proteção social que possa no Brasil romper com o ciclo estrutural de apartação social.

\section{CONSIDERAÇÕES FINAIS}

Conforme observado nas páginas anteriores, procurouse recuperar os principais aspectos fundantes do Estado de Bem-Estar Social nas economias centrais. Os três constrangimentos estruturais (lógica industrial, democracia de massa e sociedade salarial) que afincaram uma fase de exceção no capitalismo do segundo pós-guerra encontramse em crise desde o final do século XX.

O Brasil, sem ter registrado o mesmo desempenho observado nas economias centrais, apresentou ao longo do século passado uma trajetória não desprezível de evolução de seu sistema de proteção social, sobretudo a partir da Revolução de 30. De acordo com características específicas de um país periférico, o Brasil avançou em várias medidas de proteção social, sem, contudo, romper com a natureza da exclusão social.

Desde 1981, a situação social tem sido agravada, mesmo com avanços consideráveis abertos pela Constituição Federal de 1988, particularmente pelo predomínio da estagnação produtiva e pelo ciclo da financeirização da riqueza. A desestruturação do mercado de trabalho, acompanhada de políticas de corte neoliberal, combina uma nova condição de exclusão que se sobrepõe à velha exclusão herdada pelo passado colonial e escravista.

Não obstante os obstáculos e limites impostos à evolução do sistema de proteção social, o Brasil tem uma oportunidade singular de, ao democratizar a democracia, constituir um novo modelo de crescimento da renda e refazer as pazes com um futuro socialmente justo. Isso é possível, ainda que difícil de ser composto numa maioria política comprometida com o seu povo.

\section{NOTAS}

1. Sobre isso ver mais em Poulantzas (1981), Galbraith (1982) e Aglietta (1979).

2. De acordo com referência bibliográfica especializada, trata-se, neste ensaio, de identificar o especial papel que coube ao Estado cumprir nas economias de mercado desenvolvidas. Pela literatura especializa- da considera-se o conceito de Estado de Bem-Estar Social utilizado tanto na língua inglesa de Welfare State como na língua francesa de État-providence.

3. Para mais detalhes, consultar Rawls (1972) e Dumont (1988).

4. As referências foram definidas com base em Esping-Andersen (1999) e Van Parijs (1997).

5. Ver mais em Meade (1964) e Friedman (1984).

6. Sobre isso ver Schimitter e Lembruch (1979) e Korpi (1980).

7. Ver em Erikson et al. (1987) e Przeworski (1985).

8. As referências podem ser encontradas em Marshall (1950), Wilensky (1975) e Korpi (1981).

9. Sobre as fases de industrialização e impactos da Revolução Industrial, ver Hobson (1984), Ayres (1984) e Barbosa (1985).

10. Sobre padrões de sindicalismo ver Hobsbawm (1981), Bihr (1998) e Pochmann (2003).

11. Sobre o papel da organização operária e a representação de seus interesses nos partidos políticos oportunizados pelo avanço da democracia de massa, ver Przeworski (1989), Offe (1984) e Flora e Heidenheimer (1981).

12. Para alguns foi possível atender, aos grupos, problemas de convivência no interior da sociedade capitalista, como Offe (1989).

13. Para mais detalhes, ver Mattoso (1995) e Pochmann (1995).

14. Sobre a homogeneização do exercício do trabalho, ver mais em Braverman (1981), Aglietta e Brender (1984) e Boyer (1982).

15. Ver mais em Zweig (1969) e Galbraith (1956).

16. Sobre isso ver Doeringer e Piore (1985); Reich e Gordon (1975) e Maliet (1963).

17. Acerca do debate sobre a atualidade do Estado de Bem-Estar Social no centro do capitalismo mundial, ver entre outros, Kelly (2001), Coates (2000) e Boyer e Drache (1996).

18. Sobre a problemática do subdesenvolvimento, ver Furtado (1980), Arrighi (1997), Robinson (1981) e Amin (1976).

19. Entre 1930 e 1950, a variação do Produto Interno Bruto foi de $153,9 \%$ (4,8\% ao ano em média). Esse e outros dados estatísticos foram retirados de Maddison (2003).

20. Sobre a crise econômica da década de 70, responsável pelo desmoronamento do Sistema Financeiro Internacional constituído a partir de Bretton Woods, em 1944, que tinha taxas de juros fixas e paridade do dólar ao ouro, com adoção de políticas recessivas e de corte neoliberal, ver Belluzzo (1995) e Vilarreal (1984).

21. Sobre a natureza da revolução burguesa no Brasil, ver Sodré (1963) e Fernandes (1974).

22. Para mais detalhes, ver Aureliano e Draibe (1989).

23. Ver mais em Santos (1979) e Gomes (1979).

24. Para mais detalhes, ver Mestriner (2001), Sposati et al. (1985) e Fagnani (1997).

25. Acerca da natureza do Estado no Brasil ver Draibe (1985) e Oliveira (1999).

26. Para mais detalhes, ver SDTS (2003b).

27. Ver mais em Pochmann (2001) e SDTS (2003a).

\section{REFERÊNCIAS BIBLIOGRÁFICAS}

AGLIETTA, M. Regulación y crisi del capitalismo. México: Siglo Veintiuno, 1979. 
AGLIETTA, M.; BRENDER, A. Les metamorphoses de la société salariale. Paris: Calmann-Levy, 1984.

AMIN, S. O desenvolvimento desigual. Rio de Janeiro: Forense Universitária, 1976

ARRIGHI, G. A ilusão do desenvolvimento. Petrópolis: Vozes, 1997.

AURELIANO, L.; DRAIBE, S. A especificidade do Welfare State brasileiro. In: MPAS/CEPAL (Org.). A política social em tempo de crise: articulação e descentralização. Brasília: MPAS, 1989.

AYRES, R. The new industrial revolution. New York: Balbuguer, 1984.

BARBOSA, C. O processo de industrialização do capitalismo original ao atrasado. Campinas: IE/Unicamp, 1985.

BELLUZZO, L. O declínio de Bretton Woods e a emergência dos mercados globalizados. Economia e Sociedade, Campinas, IE, n.4, 1995 .

BIHR, A. Da grande noite à alternativa. São Paulo: Boitempo, 1998.

BOYER, R.; DRACHE, D. States against markets. London: Routledge, 1996.

BOYER, R. L'emploi: enjeux économique et sociaux. Paris: E. Maspero, 1982.

BRAVERMAN, H. Trabalho e capital monopolista. Rio de Janeiro: Zahar, 1981.

COATES, D. Models of capitalism. Cambridge: Polity Press, 2000.

DOERINGER, B.; PIORE, M. Internal labor markets and manpower analisys. New York: Share, 1985.

DRAIBE, S. Rumos e metamorfoses. Rio de Janeiro: Paz e Terra, 1985.

DUMONT, J. Les sistèmes etrangers de securité sociale. Paris: Econômica, 1988.

ERIKSON, E. et al. The Scandinavian model: Welfare States and Welfare Research. New York: HSP, 1987.

ESPING-ANDERSEN, G. Les trois mondes de l'État-providence. Paris: PUF, 1999.

FAGNANI, E. Política social e pactos conservadores no Brasil. Economia e Sociedade, Campinas, IE/Unicamp, n.8, p.183-238, 1997.

FERNANDES, F. A revolução burguesa no Brasil. Rio de Janeiro: Zahar, 1974.

FLORA, P.; HEIDENHEIMER, A. The development of Welfare State in Europe and América. London: T. Books, 1981.

FRIEDMAN, M. Capitalismo e liberdade. São Paulo: A. Cultural, 1984.

FURTADO, C. O mito do desenvolvimento econômico. São Paulo: Paz e Terra, 1980.

GALBRAITH, J. The affluent society. New York: H. H., 1956.

GALBRAITH, K. O novo estado industrial. São Paulo: A. Cultural, 1982.

GOMES, A. Política e legislação social no Brasil. Rio de Janeiro: Campus, 1979.

GORDON, D.; TOWNSEND, P. World poverty. Bristol: The Policy Press, 2002.

HOBSBAWM, E. Os trabalhadores. Rio de Janeiro: Paz e Terra, 1981.

HOBSON, J. A evolução do capitalismo moderno. São Paulo: A. Cultural, 1984.

KELLY, M. The divine right of capital. San Francisco: BK, 2001.

KORPI, W. The democratic class struggle. London: Routledge \& Kegan Paul, 1981.

Social policy and distributional conflict in the capitalism democracies. West European Politics, n. 3, p. 296-316, 1980.
MADDISON, A. The world economy: historical statistics. Paris: OECD, 2003.

MALIET, S. La nouvelle classe ouvrière. Paris: Seuil, 1963.

MARSHALL, T. Citizenship and social class. Cambridge: CUP, 1950

MATTOSO, J. A desordem do trabalho. São Paulo: Scritta, 1995.

MEADE, J. Efficiency, equality and the ownership of property. London: Allen \& Unwin, 1964.

MESTRINER, M. O Estado entre a filantropia e assistência social. São Paulo: Cortez, 2001.

MISHEL, L. et al. The states of working América. Cornell: CUP, 2003

OFFE, C. Capitalismo desorganizado. São Paulo: Brasiliense, 1989.

Problemas estruturais do Estado capitalista. Rio de Janeiro: Tempo Brasileiro, 1984.

OLIVEIRA, F. Privatização do público, destruição da fala e anulação da política: o totalitarismo neoliberal. In: OLIVEIRA, F.; PAOLI, M. (Orgs.). Os sentidos da democracia. Petrópolis: Vozes, 1999.

POCHMANN, M. Relações de trabalho e padrões de organização sindical no Brasil. São Paulo: LTr, 2003.

. A década dos mitos. São Paulo: Contexto, 2001.

Políticas do trabalho e de garantia de renda no capitalismo em mudanças. São Paulo: LTr, 1995.

POULANTZAS, N. Estado, poder e socialismo. Rio de Janeiro: Graal, 1981.

PRZEWORSKI, A. Capitalismo e social-democracia. São Paulo: Cia. das Letras, 1989. 1985.

Capitalism and social democracy. Cambridge: CUP,

RAWLS, J. A theory of justice. Oxford: OUP, 1972.

REICH, M.; GORDON, D. Labour segmentatio. Lexington: Heath and Co., 1975.

ROBINSON, J. Desenvolvimento e subdesenvolvimento. Rio de Janeiro: Zahar, 1981.

SANTOS, W. Cidadania e justiça. Rio de Janeiro: Campus, 1979.

SCHIMITTER, P.; LEMBRUCH, G. Trends towards corporatist intermediation. London: Sage, 1979.

SDTS. O desafio do emprego no Brasil. São Paulo: SDTS/PMSP, 2003a. $2003 \mathrm{~b}$.

SODRÉ, N. História da burguesia brasileira. Petrópolis: Vozes, 1963.

SPOSATI, A. et al. Assistência na trajetória das políticas sociais brasileiras. São Paulo: Cortez, 1985.

VAN PARIJS, P. O que é uma sociedade justa? São Paulo: Ática, 1997.

VILARREAL, R. A contra-revolução monetarista. Rio de Janeiro: Record, 1984.

WILENSKY, H. The Welfare State and equality. Berkeley: VCP, 1975.

ZWEIG, F. The worker in an affluent society. London: Heinemann, 1969.

Marcio Pochmann: Professor licenciado do Instituto de Economia e Pesquisador do Centro de Estudos Sindicais e de Economia do Trabalho da Universidade Estadual de Campinas. Secretário do Desenvolvimento, Trabalho e Solidariedade do Município de São Paulo. 